\title{
A cross-sectional study of lung functions in traffic police personnel at work in Kathmandu Valley, Nepal
}

\author{
Hari Sunder Shrestha, ${ }^{1}$ Ojashwi Nepal, ${ }^{*}{ }^{*}$ Kishor Khanal, ${ }^{3}$ Bhoopinder Kumar Kapoor ${ }^{2}$
}

BACKGROUND: The present study was aimed to assess pulmonary functions in the traffic police personnel (TPP) posted on traffic duty in Kathmandu valley, Nepal.

METHODS: The study group consisted of 17 females and 89 males, constituting $16 \%$ and $84 \%$ of the total police personnel studied, respectively. In the control group of 25 individuals, $16 \%(n=4)$ were female and $84 \%(n=21)$ were male. Portable desktop spirometer was used for the pulmonary function test (PFT) measurements.

RESULTS: It is seen that in females as compared to males, PFT parameters show a significant decrease. One-way ANOVA conducted to compare the effect of duration of air pollution exposure showed that there is a significant variation in PFT parameters among the groups. The exposure duration has significant effect on the PFT parameters.

CONCLUSION: Greater the officers are engaged in traffic duty for years, greater is the decrement in their lung functions test.

Key words: Traffic Police Pulmonary Spirometer Air Function

(C) 2015 Nepalese Association for Clinical Chemistry

\section{Introduction}

During the last few decades, air pollution of the urban atmosphere has received much attention and several studies have linked it with serious health risks especially respiratory diseases [1] According to the World Health Organization (WHO), air pollution is responsible for increase in out-patient visits, hospital admissions, and mortality due to respiratory and cardiovascular diseases [2] Traffic police personnel (TPP) working in outdoor urban environments are occupationally exposed to pollutants generated by engine combustion. A study carried out in Rome on personnel exposure to benzene found that traffic police personnel's exposures were consistently higher than those of personnel who did office work [3]. Another study conducted in Turkey showed that the TPP are the population group under risk due to the inhalation of carbon monoxide (CO) rich air while on duty at the crowded cross-sections of the city [4]. Deteriorating quality of air is a growing concern in most countries, including Nepal. Vehicular emission is the major cause of outdoor air pollution in Kathmandu Valley [5]. Bowel shape topography, temperate climate, and tropical monsoon further worsen the effect. For these reasons, the valley is classified as a High Air Pollution Potential Zone (HAPPZ) [6]. Shrestha and Malla in 1996 estimated air pollution load in Kathmandu valley by different sectors, based on the use of energy and found transport sector to have the largest contribution in total emissions followed by the household, industrial, and commercial sectors [7].

Urban air quality management strategy in Asia reported that peak particulate matter of diameter 10 microns or less (PM10) concentration is 800 microgram per cubic meter $\left(\mu \mathrm{g} / \mathrm{m}^{3}\right)$ in Kathmandu [8].Annual PM10 in high traffic area was found to be $261.4 \pm 28.5 \mu \mathrm{g} / \mathrm{m}^{3}$ [9]. Kathmandu's ambient air quality usually crosses international guidelines by two to three folds [10]. The population residing in the valley is risk group prone to develop air pollution related respiratory diseases and the most vulnerable groups include traffic police personnel, street vendors, shopkeepers, etc. Kandel reported that 6.4\% TPP studied by her in Kathmandu showed lower FEV1/FVC ratio as compared to normal [6]. Acharya concluded that TPP in Kathmandu were more exposed to particulate matter and most of them complained of fatigue, back/neck problems, arthritis, dryness of nose, forgetfulness, headache, irritation, indigestion, and stress [11] Recently, Anobha et al have demonstrated that air pollution in Kathmandu valley has substantial health impacts [12]. Shakya found that most of the personnel who were working in Kathmandu valley suffered from problems of the respiratory system and nervous system [13]. Considering these findings, the traffic police personnel, who are exposed to air pollution, are most likely to have impaired pulmonary function. Therefore,

\footnotetext{
${ }^{1}$ Department of Physiology, KIST Medical College, Imadole, Lalitpur, Nepal. ${ }^{2}$ Department of Physiology, ${ }^{3}$ Department of

Community Medicine, Kathmandu University School of Medical Sciences, Dhulikhel, Kavre, Nepal
}

Correspondence to: Ojashwi Nepal, Department of Physiology, Kathmandu University School of Medical Sciences, Dhulikhel, Kavre, Nepal. E-mail: ojan2nep@gmail.com Phone: +977-9851087866 
the present study was planned to assess pulmonary functions in the traffic police personnel posted on traffic duty in Kathmandu valley, Nepal.

\section{Methods}

This study was conducted in Kathmandu valley. The present comparative study includes randomly selected 106 TPP from those engaged in traffic control with the exposure to automobile exhausts. There are currently around 1100 traffic police personnel stationed at 33 units in the Kathmandu valley. Out of them, this study include $9 \%$ of the total number i.e. 106 traffic police personnel. This epidemiological study includes both male and female. Out of total 106 traffic police personnel 89 were male and 17 subjects were female. The "Control" includes 25 individuals involving all those in non-traffic job in Kathmandu valley. The study group consisted of 17 females and 89 males, constituting 16\% and $84 \%$ of the total police personnel studied, respectively. In the control group of 25 individuals, $16 \%(\mathrm{n}=4)$ were female and $84 \%$ $(n=21)$ were male. The ethical clearance was obtained from institutional review committee of Kathmandu University School of Medical Sciences (KUSMS) and was in accordance with the Helsinki Declaration of 1975 , as revised in 1983.

The study was conducted over a period of 6 months. Health camps were organized for the medical examination of traffic police during the study period. The first camp was conducted on 26th November 2012. Health examination and questionnaire survey was carried out in camps on Saturdays, and approximately 15 subjects were examined on each health camp.

The work experience of more than or equal to two years was required as inclusion criterion for the TPP to be included in this study. Primary data was collected from the participants of the study by direct interview based on the study questionnaire. The questionnaire survey, an occupational health questionnaire was designed based on the modified ATS-DLD-78-A (The American Thoracic Society, Division of Lung Diseases) [14]. On the day of their medical examination, written consent was taken from each of the subjects for the questionnaire survey and the medical examination. The subjects were explained about the actual procedure and purpose of the study before they were put to test.
The participants were asked not to have large meal few hours before the test and to wear loose clothes for the test. The check-up included anthropometric measurements like height in centimeter $(\mathrm{cm})$, weight in Kilogram $(\mathrm{Kg})$, calculation of Body Mass Index-BMI $\left(\mathrm{Kg} / \mathrm{m}^{2}\right)$ and measurement of blood pressure. Portable desktop spirometer, MIR Spirolab Ш was used for the PFT measurements. The procedure was conducted in the morning hours and ensured that the subject was not exposed to air pollution at least for 10 hours before the test. PFT was performed in all subjects in the standing position.

The data obtained from the questionnaire and medical examinations were analyzed using the software Microsoft Excel (MS-Excel) and Statistical Package for Social Sciences (SPSS) version 16. The data from the research were processed for mean, standard deviation, independent sample t-test, and one-way ANOVA. Descriptive statistics of the parameters were presented as means and standard deviations. Values for probability less than $0.05(\mathrm{p}<0.05)$ at $95 \%$ confidence interval were considered statistically significant.

\section{Results}

It was found that in majority of cases, the age of personnel interviewed were within the range of 26-30 years. The mean age was found to be $30.43 \pm 6.12$ years. $37 \% \quad(n=39)$ of the respondents were educated up to School Leaving Certificate, $46 \%(\mathrm{n}=49)$ up to Intermediate level, while $17 \%(\mathrm{n}=18)$ had Bachelor's degree. The majority of the study group were Constable 60\% $(\mathrm{n}=64)$ followed by Head Constable $(\mathrm{n}=19)$, Assistant Sub-Inspector $(\mathrm{n}=10)$, Sub-Inspector $(\mathrm{n}=10)$, and Inspector $(\mathrm{n}=3)$. Three percentage $(n=3)$ of the respondents were involved in the service for more than 15 years, $13 \%(\mathrm{n}=14)$ were involved in their service for $11-15$ years, $52 \%$ $(\mathrm{n}=55)$ for $6-10$ years, and $32 \%(\mathrm{n}=34)$ for $2-5$ years. Maximum number of respondent $(17 \%)$ was posted at Singha Durbar while only $4 \%$ worked at Kalimati. However, it was intimated that the duty station was usually shifted every six months. Out of the total respondents $6.6 \%(n=7)$ consumed alcohol while $15.1 \% \quad(n=16)$ chewed tobacco regularly.

Regarding personal health care by respondents such as use of PPE (Personal Protective Equipment) example mask, involvement in yoga/exercise, and health check-up, most of the respondents $(79.2 \%)$ were using masks regularly 
while $20.8 \%$ used nothing. $32.1 \%$ of the participants were involved in physical activities like yoga/exercise and $18.9 \%$ of the respondents visited medical personnel for their health checkup on yearly basis.

It was found that there was no significant difference between the two groups for age [study group, $30.43 \pm 6.12$ years Vs control group, $31.60 \pm 7.98$ years, $\mathrm{p}=0.499$ ], weight [study group, $66.42 \pm 10.10 \mathrm{~kg}$ Vs control group, $64.76 \pm 15.80 \mathrm{~kg}, p=0.514$ ], BMI [study group, $22.55 \pm 3.26 \mathrm{~kg} / \mathrm{m}^{2} \mathrm{Vs}$ control group, $23.18 \pm 4.76$ $\left.\mathrm{kg} / \mathrm{m}^{2}, \mathrm{p}=0.428\right]$, and body surface area (BSA) [study group, $1.77 \pm 0.14 \mathrm{~m}^{2} \mathrm{Vs}$ control group, $\left.1.72 \pm 0.20 \mathrm{~m}^{2}, \mathrm{p}=0.102\right]$. However, there was no consistency in the height of individuals in both groups [study group, $171.62 \pm 6.89 \mathrm{~cm} \mathrm{Vs} \mathrm{control}$ group, $166.80 \pm 9.06 \mathrm{~cm}, \mathrm{p}=0.018]$.

Table 1 shows the results of PFT obtained in traffic police personnel along with the comparison of PFT parameters between TPP (study group) and control group. There is significant decrease in parameters like forced vital capacity (FVC), forced vital capacity expressed as body surface area (FVC_BSA), forced expiratory volume in 1 second (FEV1) forced expiratory volume in 1 second expressed as body surface area (FEV1_BSA), peak expiratory flow rate (PEFR), peak expiratory flow rate expressed as body surface area (PEFR_BSA), forced expiratory flow at $25 \%$ of volume as a percentage of FVC (FEF25\%), maximum voluntary ventilation (MVV), and maximum voluntary ventilation expressed as body surface area (MVV_BSA) at $\mathrm{p}$ value $<0.01$ level, a significant decrease in forced expiratory flow at $25 \%$ of volume as a percentage of FVC expressed as body surface area (FEF25\%_BSA) at $\mathrm{p}$ value $<0.05$ level while no significant gender difference in $\mathrm{FEV} 1 / \mathrm{FVC} \%$, forced expiratory flow at $25-75 \%$ of volume as a percentage of FVC (FEF25\%-75\%) and forced expiratory flow at $25-75 \%$ of volume as a percentage of FVC expressed as body surface area (FEF25\%-75\%_BSA) was found.

Table 2 shows that within the study group, comparing the PFT parameters between personnel on traffic duty for less than eight years and those for eight or more years, a significant decreases in parameters like FVC, FEV1, FEF25\%-75\%, forced expiratory flow at 50\% of volume as a percentage of FVC (FEF50\%), forced expiratory flow at $75 \%$ of volume as a percentage of FVC (FEF75\%), and MVV (all expressed per square meter body surface area) were found in personnel on traffic duty for more than eight years.

A one-way ANOVA as shown in Table 3 was conducted to compare the effect of duration of air pollution exposure. For this purpose, the study sample personnel were divided into four groups, based on the duration of their traffic duty in years: Group I 2-5 years, Group II 6-10 years, Group III 11-15 years, and Group IV > 15 years. There is a significant variation in PFT parameters like FVC_BSA, FEV1_BSA, FEF75\%, and FEF75\%_BSA among the groups.

Table 1. Comparison of PFT parameters between TPP (study group) and control group

\begin{tabular}{|c|c|c|c|}
\hline Parameters & Study group $(n=106)$ & Control group $(n=25)$ & $p$ value \\
\hline FVC (L) & $4.01 \pm 0.66$ & $4.09 \pm 0.49$ & 0.496 \\
\hline FVC_BSA & $2.25 \pm 0.33$ & $2.39 \pm 0.32$ & 0.058 \\
\hline $\mathrm{FEV}_{1}(\mathrm{~L})$ & $3.35 \pm 0.57$ & $3.41 \pm 0.57$ & 0.635 \\
\hline $\mathrm{FEV}_{1-B S A}$ & $1.89 \pm 0.30$ & $2.00 \pm 0.35$ & 0.114 \\
\hline $\mathrm{FEV}_{1} / \mathrm{FVC} \%$ & $83.88 \pm 6.66$ & $83.27 \pm 7.25$ & 0.690 \\
\hline PEFR (L/s) & $8.28 \pm 1.95$ & $8.75 \pm 1.38$ & 0.172 \\
\hline PEFR_BSA & $4.66 \pm 1.04$ & $5.11 \pm 0.75$ & $0.042^{*}$ \\
\hline $\mathrm{FEF}_{25 \%-75 \%}(\mathrm{~L} / \mathrm{s})$ & $3.80 \pm 1.087$ & $4.42 \pm 0.98$ & $0.011^{*}$ \\
\hline $\mathrm{FEF}_{25 \%-75 \%-} \mathrm{BSA}$ & $2.15 \pm 0.63$ & $2.59 \pm 0.59$ & $0.002^{*}$ \\
\hline $\mathrm{FEF}_{25 \%}(\mathrm{~L} / \mathrm{s})$ & $6.70 \pm 1.87$ & $7.48 \pm 1.12-$ & $0.009^{*}$ \\
\hline $\mathrm{FEF}_{25 \%-} \mathrm{BSA}$ & $3.76 \pm 1.00$ & $4.38 \pm 0.66$ & $0.000^{* *}$ \\
\hline $\mathrm{FEF}_{50 \%}(\mathrm{~L} / \mathrm{s})$ & $4.22 \pm 1.22$ & $4.71 \pm 1.07$ & 0.067 \\
\hline FEF $_{50 \%-}$ BSA & $2.38 \pm 0.70$ & $2.76 \pm 0.63$ & $0.016^{*}$ \\
\hline $\mathrm{FEF}_{75 \%}(\mathrm{~L} / \mathrm{s})$ & $1.75 \pm 0.70$ & $2.20 \pm 0.99$ & $0.039^{*}$ \\
\hline $\mathrm{FEF}_{75 \% \_} \mathrm{BSA}$ & $0.99 \pm 0.43$ & $1.28 \pm 0.56$ & $0.006^{*}$ \\
\hline $\mathrm{MVV}(\mathrm{L} / \mathrm{min})$ & $130.92 \pm 27.08$ & $129.81 \pm 35.55$ & 0.885 \\
\hline MVV_BSA & $73.80 \pm 14.87$ & $76.32 \pm 21.48$ & 0.583 \\
\hline
\end{tabular}

Values are Mean \pm SD; n: number of participants

** Correlation is significant at the 0.01 level (2-tailed).

* Correlation is significant at the 0.05 level (2-tailed). 
There is significant effect of exposure duration on $\mathrm{FVC}\left(\mathrm{L} / \mathrm{m}^{2}\right) \quad[\mathrm{F}=4.299, \mathrm{p}=0.007]$, on FEV1 $\left(\mathrm{L} / \mathrm{m}^{2}\right)[\mathrm{F}=4.232, \mathrm{p}=0.007]$, and on $\mathrm{FEF} 75 \%$ $\left(\mathrm{L} / \mathrm{s} / \mathrm{m}^{2}\right)[\mathrm{F}=4.400, \mathrm{p}=0.006]$, in the aforementioned four groups.

Further, Post hoc comparisons using the LSD test indicated that the mean $\mathrm{FVC}\left(\mathrm{L} / \mathrm{m}^{2}\right)$ of Group I TPP to whom duration of exposure was 2 to 5 years $\left(2.28 \pm 0.34 \mathrm{~L} / \mathrm{m}^{2}\right)$ was significantly different from the mean FVC $\left(\mathrm{L} / \mathrm{m}^{2}\right)$ of Group
III TPP to whom duration of exposure was 11 years to 15 years $\left(2.07 \pm 0.28 \mathrm{~L} / \mathrm{m}^{2}\right)$ and Group IV TPP to whom exposure duration was more than 15 years $\left(1.79 \pm 0.13 \mathrm{~L} / \mathrm{m}^{2}\right)$.

Post hoc comparisons using the LSD test indicated that the mean FEV1 $\left(\mathrm{L} / \mathrm{m}^{2}\right)$ of Group I TPP $\left(1.96 \pm 0.35 \mathrm{~L} / \mathrm{m}^{2}\right)$ was significantly different from the mean FEV1 $\left(\mathrm{L} / \mathrm{m}^{2}\right)$ of Group III TPP $\left(1.71 \pm 0.20 \mathrm{~L} / \mathrm{m}^{2}\right)$ and Group IV TPP $(1.50 \pm 0.16$ $\left.\mathrm{L} / \mathrm{m}^{2}\right)$.

Table 2 Comparison of PFT parameters between TPP exposed to less than eight years and TPP exposed to eight or more years.

\begin{tabular}{|c|c|c|c|}
\hline \multirow[t]{2}{*}{ Parameters } & \multicolumn{2}{|c|}{ Duration of exposure } & \multirow[t]{2}{*}{$\mathrm{p}$ value } \\
\hline & $<8$ years $(n=65)$ & $\geq 8$ years $(n=41)$ & \\
\hline FVC_BSA & $2.34 \pm 0.32$ & $2.11 \pm 0.29$ & $0.000^{* *}$ \\
\hline $\mathrm{FEV}_{1 \_} \mathrm{BSA}$ & $1.97 \pm 0.32$ & $1.75 \pm 0.22$ & $0.000^{* *}$ \\
\hline $\mathrm{FEV}_{1} / \mathrm{FVC} \%$ & $84.12 \pm 7.41$ & $83.49 \pm 5.33$ & 0.639 \\
\hline PEFR_BSA & $4.67 \pm 1.07$ & $4.64 \pm 0.99$ & 0.877 \\
\hline $\mathrm{FEF}_{25 \%-75 \% \_} \mathrm{BSA}$ & $2.26 \pm 0.69$ & $1.96 \pm 0.45$ & $0.009^{*}$ \\
\hline $\mathrm{FEF}_{25 \% \_} \mathrm{BSA}$ & $3.78 \pm 1.01$ & $3.73 \pm 0.98$ & 0.812 \\
\hline $\mathrm{FEF}_{50 \%-B S A}$ & $2.48 \pm 0.78$ & $2.22 \pm 0.52$ & $0.038^{*}$ \\
\hline $\mathrm{FEF}_{75 \%-\mathrm{BSA}}$ & $1.09 \pm 0.49$ & $0.84 \pm 0.25$ & $0.001^{* *}$ \\
\hline MVV_BSA & $76.66 \pm 14.86$ & $69.28 \pm 13.89$ & $0.012^{*}$ \\
\hline
\end{tabular}

Values are Mean \pm SD; n: number of participants

** Correlation is significant at the 0.01 level (2-tailed).

* Correlation is significant at the 0.05 level (2-tailed).

Table 3. One-way ANOVA for comparison of pulmonary function tests of TPP according to duration of exposure

\begin{tabular}{|c|c|c|c|c|c|c|}
\hline Parameters & $\begin{array}{l}2-5 \text { years } \\
(n=34)\end{array}$ & $\begin{array}{l}6-10 \text { years } \\
(n=55)\end{array}$ & $\begin{array}{l}11-15 \\
(n=14)\end{array}$ & $\begin{array}{l}>15 \\
(n=3)\end{array}$ & F value & $\mathrm{p}$ value \\
\hline$\overline{\mathrm{FVC}(\mathrm{L})}$ & $3.96 \pm 0.75$ & $4.12 \pm 0.60$ & $3.78 \pm 0.62$ & $3.46 \pm 0.61$ & 1.897 & 0.135 \\
\hline $\mathrm{FVC}\left(\mathrm{L} / \mathrm{m}^{2}\right)$ & $2.28 \pm 0.34$ & $2.30 \pm 0.31$ & $2.07 \pm 0.28$ & $1.79 \pm 0.13$ & 4.299 & $0.007^{* *}$ \\
\hline $\mathrm{FEV}_{1}(\mathrm{~L})$ & $3.38 \pm 0.68$ & $3.42 \pm 0.52$ & $3.12 \pm 0.45$ & $2.89 \pm 0.60$ & 1.688 & 0.174 \\
\hline $\operatorname{FEV}_{1}\left(\mathrm{~L} / \mathrm{m}^{2}\right)$ & $1.96 \pm 0.35$ & $1.91 \pm 2.27$ & $1.71 \pm 0.20$ & $1.50 \pm 0.16$ & 4.232 & $0.007^{* *}$ \\
\hline $\mathrm{FEV}_{1} \%$ & $85.64 \pm 6.95$ & $83.03 \pm 6.64$ & $83 \pm 6.24$ & $83.45 \pm 3.52$ & 1.182 & 0.320 \\
\hline PEFR (L/s) & $8.04 \pm 2.07$ & $8.56 \pm 1.91$ & $7.65 \pm 1.93$ & $8.98 \pm 0.15$ & 1.156 & 0.331 \\
\hline $\operatorname{PEFR}\left(\mathrm{L} / \mathrm{s} / \mathrm{m}^{2}\right)$ & $4.63 \pm 1.01$ & $4.78 \pm 1.07$ & $4.20 \pm 1.02$ & $4.71 \pm 0.43$ & 1.185 & 0.319 \\
\hline $\mathrm{FEF}_{25 \%-75 \%}(\mathrm{~L} / \mathrm{s})$ & $3.97 \pm 1.21$ & $3.80 \pm 1.04$ & $3.57 \pm 0.90$ & $3.11 \pm 0.90$ & 0.902 & 0.443 \\
\hline $\mathrm{FEF}_{25 \%-75 \%}\left(\mathrm{~L} / \mathrm{s} / \mathrm{m}^{2}\right)$ & $2.32 \pm 0.74$ & $2.12 \pm 0.57$ & $1.96 \pm 0.49$ & $1.60 \pm 0.32$ & 2.065 & 0.110 \\
\hline $\mathrm{FEF}_{25 \%}(\mathrm{~L} / \mathrm{s})$ & $6.44 \pm 1.63$ & $6.93 \pm 2.07$ & $6.33 \pm 1.71$ & $7.06 \pm 1.16$ & 0.701 & 0.553 \\
\hline $\mathrm{FEF}_{25 \%}\left(\mathrm{~L} / \mathrm{s} / \mathrm{m}^{2}\right)$ & $3.72 \pm 0.85$ & $3.87 \pm 1.12$ & $3.48 \pm 0.92$ & $3.68 \pm 0.41$ & 0.575 & 0.633 \\
\hline $\mathrm{FEF}_{50 \%}(\mathrm{~L} / \mathrm{s})$ & $4.35 \pm 1.34$ & $4.23 \pm 1.21$ & $3.97 \pm 1.09$ & $3.56 \pm 0.63$ & 0.603 & 0.614 \\
\hline $\mathrm{FEF}_{50 \%}\left(\mathrm{~L} / \mathrm{s} / \mathrm{m}^{2}\right)$ & $2.53 \pm 0.80$ & $2.36 \pm 0.66$ & $2.18 \pm 0.60$ & $1.85 \pm 0.14$ & 1.507 & 0.217 \\
\hline $\mathrm{FEF}_{75 \%}(\mathrm{~L} / \mathrm{s})$ & $2.01 \pm 0.94$ & $1.69 \pm 0.52$ & $1.47 \pm 0.44$ & $1.20 \pm 0.66$ & 3.159 & $0.028^{*}$ \\
\hline $\mathrm{FEF}_{75 \%}\left(\mathrm{~L} / \mathrm{s} / \mathrm{m}^{2}\right)$ & $1.18 \pm 0.59$ & $0.94 \pm 0.29$ & $0.81 \pm 0.24$ & $0.61 \pm 0.28$ & 4.400 & $0.006^{* *}$ \\
\hline MVV (L/min) & $129.32 \pm 29.56$ & $134.64 \pm 26.0$ & $122.91 \pm 26.45$ & $118 \pm 12.63$ & 1.023 & 0.389 \\
\hline $\operatorname{MVV}\left(\mathrm{L} / \mathrm{min} / \mathrm{m}^{2}\right)$ & $74.86 \pm 15.14$ & $75.49 \pm 15.07$ & $67.20 \pm 12.62$ & $61.77 \pm 6.57$ & 1.916 & 0.132 \\
\hline
\end{tabular}

Values are Mean \pm SD; n: number of participants

** Correlation is significant at the 0.01 level (2-tailed).

* Correlation is significant at the 0.05 level (2-tailed). 
In addition, the mean FEV1 $\left(\mathrm{L} / \mathrm{m}^{2}\right)$ of Group II TPP $\left(1.91 \pm 2.27 \mathrm{~L} / \mathrm{m}^{2}\right)$ was significantly different from the mean FVC $\left(\mathrm{L} / \mathrm{m}^{2}\right)$ of Group III TPP $\left(1.71 \pm 0.20 \mathrm{~L} / \mathrm{m}^{2}\right)$ and Group IV TPP $(1.50 \pm 0.16$ $\left.\mathrm{L} / \mathrm{m}^{2}\right)$. The mean FEV1 $\left(\mathrm{L} / \mathrm{m}^{2}\right)$ of Group I TPP $\left(1.96 \pm 0.35 \mathrm{~L} / \mathrm{m}^{2}\right)$ did not significantly differ from the mean FEV1 $\left(\mathrm{L} / \mathrm{m}^{2}\right)$ of Group II TPP $\left(1.91 \pm 2.27 \mathrm{~L} / \mathrm{m}^{2}\right)$. Also, the mean FEV1 $\left(\mathrm{L} / \mathrm{m}^{2}\right)$ of Group III TPP $\left(1.71 \pm 0.20 \mathrm{~L} / \mathrm{m}^{2}\right)$ did not significantly differ from the mean FEV1 $\left(\mathrm{L} / \mathrm{m}^{2}\right)$ of Group IV TPP $\left(1.50 \pm 0.16 \mathrm{~L} / \mathrm{m}^{2}\right)$.

Post hoc comparisons using the LSD test indicated that the mean FEF75\% $\left(\mathrm{L} / \mathrm{s} / \mathrm{m}^{2}\right)$ of Group I TPP $\left(1.18 \pm 0.59 \mathrm{~L} / \mathrm{s} / \mathrm{m}^{2}\right)$ was significantly different from the mean FEF75\% $\left(\mathrm{L} / \mathrm{s} / \mathrm{m}^{2}\right)$ of Group II TPP $\left(0.94 \pm 0.29 \mathrm{~L} / \mathrm{s} / \mathrm{m}^{2}\right)$, Group III TPP $\left(0.81 \pm 0.24 \mathrm{~L} / \mathrm{s} / \mathrm{m}^{2}\right)$, and Group $\operatorname{IV} \operatorname{TPP}\left(0.61 \pm 0.28 \mathrm{~L} / \mathrm{s} / \mathrm{m}^{2}\right)$.

The mean FEF75\% $\left(\mathrm{L} / \mathrm{s} / \mathrm{m}^{2}\right)$ of Group II TPP $\left(0.94 \pm 0.29 \mathrm{~L} / \mathrm{s} / \mathrm{m}^{2}\right)$ did not significantly differ from the mean FEF75\% $\left(\mathrm{L} / \mathrm{s} / \mathrm{m}^{2}\right)$ of Group III TPP $\left(0.81 \pm 0.24 \mathrm{~L} / \mathrm{s} / \mathrm{m}^{2}\right)$ and Group IV TPP $\left(0.61 \pm 0.28 \mathrm{~L} / \mathrm{s} / \mathrm{m}^{2}\right)$. Also, the mean FEF75\% $\left(\mathrm{L} / \mathrm{s} / \mathrm{m}^{2}\right)$ of Group III TPP $\left(0.81 \pm 0.24 \mathrm{~L} / \mathrm{s} / \mathrm{m}^{2}\right)$ did not significantly differ from the mean FEF75\% $\left(\mathrm{L} / \mathrm{s} / \mathrm{m}^{2}\right)$ of Group IV TPP $(0.61 \pm 0.28$ $\left.\mathrm{L} / \mathrm{s} / \mathrm{m}^{2}\right)$.

The prevalence of various respiratory symptoms on the basis of the analysis of the questionnaire, cough was present in 41 volunteers, phlegm in 34 individuals, breathlessness in 27 of them, and chest illness in 7 subjects among 106 cases studied.

\section{Discussion}

The PFT parameters of most of the TPP were within the normal range. But when they were compared with the control group, it was found that they were significantly inferior to those of controls. The Spiro metric parameters PEFR, FEF25\%-75\%, FEF25\%, FEF50\%, and FEF75\% all expressed per square meter body surface area were significantly reduced in TPP than in controls.

FVC per square meter body surface area statistically did not show significant difference between traffic police personnel and controls. However, there was slight decrease in the value for the study group. Volume of air expired in the 1st second of the test expressed as BSA was also statistically insignificant between both the groups. However, there was slight decrease in the value for the study group. These findings contradict those of Wonsurakiat et al., Singh et al., Pal et al., and Sharat et al. who found consistent difference in FVC and FEV1 between TPP exposed to vehicular emission and those not exposed [15-18].

The FEV1/FVC ratio is a better indicator of the condition of the bronchial musculatures. FEV1 percentage of FVC in both the groups was found statistically insignificant.

Peak expiratory flow rate (PEFR), which is also termed maximal expiratory flow, occurs shortly after the onset of expiration. The PEFR, more than the other measures, is dependent on participant's effort, thus signifying the capacity of expiratory muscles. In this study, the significant decrease in PEFR value in case of TPP indicates that there was some obstruction during expiration. This is similar to the finding of other investigators $[19,20]$.

FEF25\%-75\% indicates flow rates in small airways i.e. those with internal diameters of less than two millimeter. Decrease in FEF25\%-75\% suggests greater involvement of small airways. The average forced expiratory flow rate over the middle $50 \%$ of the FVC (FEF25\%-75\%) which explains the patency of smaller airways was found to be significantly different between both the groups with higher reduction in the value in case of exposed traffic police personnel. The FEF25\%-75\% being relatively sensitive index of airflow obstruction and may be abnormal when the FEV1/FVC ratio is still preserved. It is affected by the airway resistance during forced expiration.

Increased average levels of total suspended particles (TSP) over a 4-days period are significantly associated with decrements in FVC, FEV1, and FEF25\%-75\% [21].

In the present study FEF25\% expressed per square meter body surface area of TPP (which suggests conditions of larger airways) was also significantly decreased. Reduction in both FEF25\%-75\% and FEF25\% in TPP suggests that the airways in generalare narrowed preventing the free flow of air during respiration. Similar results were reported by Pal et al. [17]. FEF $50 \%$ and FEF75\% both expressed per square meter body surface area were also found to be significantly reduced in TPP as compared to control groups. 
Maximum voluntary ventilation (MVV) is dependent on the muscular development of the individual. The subject is instructed to breathe as hard and fast as possible for 10 to 15 seconds. The result is extrapolated to 60 seconds and reported in liters per minute. A low MVV can occur in obstructive disease, in restrictive disease, in neuromuscular disease, in heart disease, in a patient who does not try hard enough or does not understand how to perform the test, or in a frail patient. Thus, this test is very nonspecific, and yet it correlates well with a subject's exercise capacity and with the complaint of dyspnea. In this study, MVV though statistically not significant, was found to be decreased in TPP.

Comparison of PFT parameters between personnel on traffic duty for eight or more years and those for less than eight years showed significant decrease in parameters like FVC, FEV1, FEF25\%-75\%, FEF50\%, FEF75\%, and MVV (all expressed per square meter body surface area) in greater exposed personnel. This finding was similar with the study of Gupta et al. [18].

Comparison of PFT parameters (expressed per $\mathrm{m}^{2}$ BSA) among TPP in different groups, representing duration for which they have been on traffic duty revealed significant decreases, the magnitude of decrease in many PFT parameters being broadly correlated with the duration of traffic duty. This suggests that increase in the duration of traffic duty (in years) has increasingly harmful effect on lung function in traffic police personnel.

No significant differences were found in FVC and FEV1 between Group I and Group II TPP. FEF75\% in Group I TPP significantly differs from that in other groups of TPP with the successive reduction in their values in Group II and III. In this study pulmonary function tests like FVC $\left(\mathrm{L} / \mathrm{m}^{2}\right)$ and FEV1 $\left(\mathrm{L} / \mathrm{m}^{2}\right)$ in Group II TPP were not significantly different from those in Group I, but FEF75\% (L/s) and FEF75\% $\left(\mathrm{L} / \mathrm{s} / \mathrm{m}^{2}\right)$ were. The most sensitive measure in our study was found to be FEF75\%.

Although TPP in Group IV showed the same trend, a large sample is needed for definite quantitative analysis of PFT in TPP exposed for more than 15 years. Their PFT parameters were not subjected to statistical comparisons, since the number of TPP in this group was small (only 3 ).

These findings suggest that the exposure duration has significant effect on the PFT parameters; greater the officers are engaged in traffic duty for years, greater is the decrement in their lung functions tests.

There is a normal gender dependent physiological variation in Spiro metric test values. Males usually show higher values than the females [22]. In this study, comparison of PFT parameters between male TPP and female TPP showed lower values of FVC, FEV1, PEFR, FEF25\%, and MVV (all expressed per square meter BSA) in the female TPP than in the male TPP.

The number of females in the study was 17 . Only 5 of them were on traffic police duty for more than 5 years. Thus the great majority of them were involved in traffic control duty only for a short period of time (2-5 years). And yet, the female TPP showed a far greater reduction in PFT parameters than their male colleagues.

Detailed work on a larger number of women TPP involved in traffic duty over a prolonged period of time is required to further explain and elucidate the present findings.

The questionnaire survey carried out among TPP and the controls revealed that many of the participants had short term respiratory effects such as cough, phlegm, and breathlessness confirming the findings of other studies $[6,11$, $13,18]$.

Traffic police personnel in Kathmandu have been provided with masks to wear while on duty. Many of them reported that they found it inconvenient to wear, as on many an occasion, it interfered with their duties (like need to whistle!). However, the present study did not study the effect of wearing or not wearing a mask on the PFT.

\section{Conclusion}

This study showed that the adverse health impacts of automobile pollution can be significant. This reduction in pulmonary function can be detected with the help of spirometry before appearance of major symptoms or before pulmonary functions are grossly impaired.

\section{Acknowledgement}

We are thankful to the traffic personnel who volunteered in the study despite their busy schedule. Many thanks to 'Metropolitan Traffic Police Division', Singha Durbar at Kathmandu 
valley for their co-operation in this study. We also thank Dhulikhel Hospital for providing the portable spirometer during the study.

\section{REFERENCES}

1. Tuladhar B. Health impacts of Kathmandu's air pollution. Clean Energy Nepal, Environment and Public Health Organization. http://www.cleanairinitiative.org/por tal/system/files/59152_tuladharpape r.doc. Published September 2003. Accessed July 10, 2012

2. Krzyzanowski M, Cohen A. Update of $\mathrm{WHO}$ air quality guidelines. Air QualAtmos Health. 2008;1:713.doi:10.1007/s11869-008-0008-9.

3. Crebelli R, Tomei F, Zijno A, et al. Exposure to benzene in urban workers: Environmental and biological monitoring of traffic police in Rome. Occup Environ Med. 2001;58:165-71.

4. Burgaz S, Demircigil GC, Karahalil $\mathrm{B}$, et al. Chromosomal damage in peripheral blood, lymphocytes of traffic policemen, and taxi drivers exposed to urban air pollution. Chemosphere. 2002;47:57-64.

5. Sapkota RC. Vehicular pollution in Kathmandu valley. Journal of the Institute of Engineering.2010;8:14952.

6. Kandel P. Study on respiratory health conditions of traffic police personnel working in Kathmandu valley [dissertation]. Kavre: Kathmandu University; 2009.

7. Shrestha RM, Malla S. Air pollution from energy use in developing country city: case of Kathmandu Valley. Energy.1996;21:785-94.

8. Shah JJ, Nagpal T. Urban air quality management strategy in Asia: Kathmandu Valley Report. The World Bank-Technical paper, 378. www.lib.icimod.or/record/4824.Up dated 1997. Accessed July 10, 2012.
9. Sapkota BK. Study of visibility and particulate pollution over Kathmandu valley [dissertation]. Kathmandu: Pulchowk Campus; 1996.

10. Majumder AK, Nazmul Islam KM, Bajracharya RM, Carter WS. Assessment of occupational and ambient air quality of traffic police personnel of the Kathmandu valley, Nepal; in view of atmosphericparticulate matter concentrations (PM10). Atmospheric Pollution Research. 2011;3:132-42.

11. Acharya $S$. The occupational health status of traffic police personnel working in Kathmandu valley [dissertation]. Kavre: Kathmandu University; 2009.

12. Gurung A, Bell ML. Exposure to airborne particulate matter in Kathmandu Valley, Nepal. J Expo Sci Environ Epidemiol. 2012;22:235-42

13. Shakya S. Health problems prevalent in traffic police personnel due to vehicular air pollution in Kathmandu [dissertation]. Kathmandu: St. Xavier's College; 2001.

14. Boehlecke BA, Merchant JA.The use of pulmonary function testing and questionnaires as epidemiologic tools in the study of occupational lung disease. Chest. 1981 Apr;79(4Suppl). PubMed PMID: 7471883.

15. Wongsurakiat P, Maranetra KN, Nana A, et al. Respiratory symptoms and pulmonary function of traffic policemen in Thonburi. J Med
Assoc Thai. 1999 May;82(5):43543. PubMed PMID: 10443092.

16. Singh V, Sharma BB, Yadav R, Meena P. Respiratory Morbidity attributed to auto-exhaust pollution in traffic policemen of Jaipur, India. J Asthma. 2009 March;46(2):11821. PubMed PMID: 19253114.

17. Pal P, John RA, Dutta TK, Pal GK. Pulmonary function test in traffic police personnel in Pondicherry. Indian J Physiol Pharmacol. 2010;54:329-36.

18. Gupta S, Mittal S, Kumar A, Singh KD. Respiratory effects of air pollutants among nonsmoking traffic policemen of Patiala, India. Lung India. 2011;28:253-57.

19. Hirimuthugoda LK, Wathudura SPK, Edirimanna H, Madarasingha HP. Lung functions among Traffic and Non-traffic police officers in Colombo Division. Proceedings of Annual Scientific Sessions of Faculty of Medical Sciences; 2012 Dec 7; Sri Lanka.

20. Ingle ST, Pachpande BG, Wagh ND, Patel VS, Attarde SB. Exposure to vehicular pollution and respiratory impairment of traffic policemen in Jalgaon City, India. Ind Health. 2005;43:656-62.

21. Abbey DE, Burchette RJ, Knutsen SF, McDonnell WF, Lebowitz MD, Enright PL. Long term particulates and other air pollutants and lung function in nonsmokers. Am J Respir. 1998;158:289-98.

22. Wenberger SE. Principle of pulmonary medicine. 3rd ed. Philadelphia: WB Saunders; 1986. 